\title{
Treatment of adult rhabdoid renal cell carcinoma with sorafenib
}

\author{
Anil Kapoor, MD; ${ }^{*}$ Robert Tutino, MD; ${ }^{*}$ Androniki Kanaroglou, $M D ;{ }^{*}$ Sebastien J. Hotte, $M D^{\dagger}$
}

\begin{abstract}
Renal cell carcinoma (RCC) with rhabdoid features is an uncommon and highly aggressive malignancy. We report a case of adult clear-cell RCC with extensive rhabdoid features treated with the tyrosine kinase inhibitor sorafenib. A review of the literature summarizes important aspects of this malignancy. We discuss clinical and histological findings as well as the patient's response to sorafenib therapy.
\end{abstract}

Can Urol Assoc J 2008;2(6):631-4

\section{Introduction}

Adult clear-cell renal cell carcinoma (RCC) with extensive rhabdoid features is a rare clinical entity. Renal cell carcinoma with rhabdoid features is an uncommon and highly aggressive malignancy most often found in the pediatric population. Although only few cases of adult pure rhabdoid renal tumours are reported, Gokden and colleagues $^{1}$ found that $5 \%$ of RCC exhibited rhabdoid features. Despite the relative rarity of rhabdoid features, they are universally recognized as an indicator of a highly aggressive neoplasm. ${ }^{2}$ Little success has been reported in treating patients with these tumours.

Antiangiogenic therapy is the use of drugs or other substances to alter the flow of blood around or to a tumour. Vascular endothelial growth factor (VEGF) can be inhibited through a number of mechanisms. Agents such as bevacizumab target VEGF directly and other small molecule tyrosine kinase inhibitors target receptors to VEGF and inhibit downstream cell signaling. Examples of these orally available compounds are sunitinib and sorafenib. Newer agents such as temsirolimus and everolimus target the mammalian target of rapamycin pathway and inhibit downstream cell signaling, leading to the inhibition of further VEGF production.

Current tyrosine kinase inhibitors (e.g., sorafenib, sunitinib) have revolutionized the treatment of conventional clear-cell RCC. However, atypical pathology has usually been an exclusion for most tyrosine kinase inhibitor trials. We present the treatment results of a rare, atypical RCC with rhabdoid features treated with the tyrosine kinase inhibitor sorafenib. A review of the literature about adult rhabdoid RCC highlights important aspects of this malignancy.

\section{Method}

The medical records of a 47-year-old female patient with clear-cell RCC with extensive rhabdoid features were searched. Consultation notes, operating room notes, pathological records and other relevant documents were used as a resource to compile information on this case. We also included recent assessments of the patient in this report. A literature review was conducted using a search of EMBASE, MEDLINE/PubMed and the Cochrane Database. We used the search terms "rhabdoid," "renal cell carcinoma," "adult" and "tumor." References of articles found were also searched for relevant articles.

\section{Case}

A 47-year-old woman presented to her family physician with a 3-month history of leftsided flank pain and nausea. On physical examination a hard palpable mass was found in her abdomen. Her past medical history included hypertension, migraine headaches, anemia and a previous right inguinal hernia. She had no family history of urological malignancies, but had a paternal cousin with colon cancer and paternal uncle with lung cancer. The patient was a lifelong nonsmoker.

Ultrasonography of her abdomen revealed a complex hypervascular mass in the upper pole of her left kidney measuring $11.1 \times 11.8$ $\times 7.5 \mathrm{~cm}$. The mass enlarged the left kidney to $16.0 \mathrm{~cm}$ in length. The right kidney appeared to be healthy. A contrast-enhanced computed tomograpy scan showed a hypervascular tumour in her left kidney infiltrating the left psoas and spleen, with evidence of retroperitoneal lymphadenopathy and tumour thrombus extending to the infrahepatic vena cava. Lesions highly suspected as metastastic deposits were found in the liver. A chest radiograph showed multiple nodules in both lung fields, also suggestive of metastatic disease. A bone scan revealed an ill-defined area in the left sixth rib and abnormal uptake in both distal femurs, consistent with metastasis to these sites. 
Kapoor et al.

An open left radical nephrectomy was performed through a chevron incision. The left kidney mass was removed en bloc with the adrenal gland and the thrombus was treated with venacavotomy and thrombectomy. Hard lymphadenopathy was resected along the aorta to the level of the aortic bifurcation.

Gross pathology revealed a kidney weighing $460 \mathrm{~g}$. The upper pole was occupied by a large irregularly lobulated tumour, measuring $14.5 \times$ $8.5 \times 8.0 \mathrm{~cm}$. The tumour had infiltrated the renal capsule and extended into the perinephric adipose tissues, and had invaded the renal vein.

Histologically, the tumour was a clear-cell RCC with very extensive rhabdoid features and was Fuhrman nuclear grade 3 (Fig. 1). The tumour cells demonstrated hyaline globular inclusions, vesicular nuclei and prominent nucleoi (Fig. 2). Vimentin was strongly positive (Fig. 3 and Fig. 4).

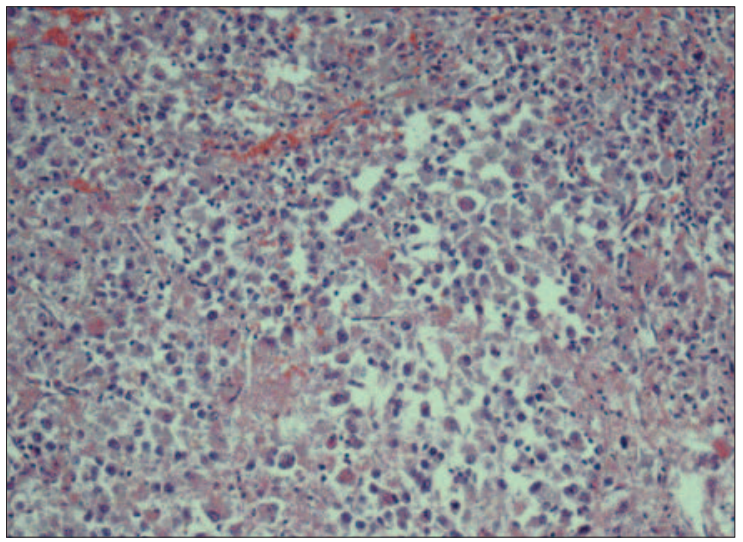

Fig. 1. Histological section showing rhabdoid features with areas of necrosis (hematoxylin-eosin stain, original magnification $\times 20$ ).

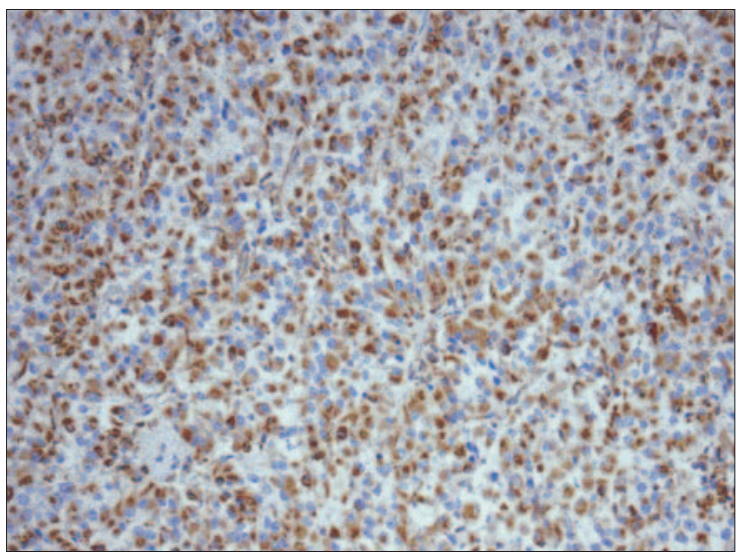

Fig. 3. Histological section showing tumour cells strongly positive (vimentin stain, original magnification $\times 20$ ).
Postoperatively, the patient recovered uneventfully and was subsequently referred to the regional cancer centre, where chemotherapy treatment with doxorubicin and gemcitabine were discussed with the patient. Tyrosine kinase inhibition was also discussed with the patient, specifically detailing the results with conventional clear-cell RCC histology, and the paucity of data regarding the effectiveness of tyrosine kinase inhibitors in atypical histology. After a 1-month course of conventional chemotherapy, disease progression was documented and sorafenib $400 \mathrm{mg}$ twice a day orally was initiated after extensive discussion with the patient. Eleven months postoperatively, the patient was alive and living at home with her family, with stable disease. She was tolerating sorafenib with minimal side effects, and dose reduction was not necessary.

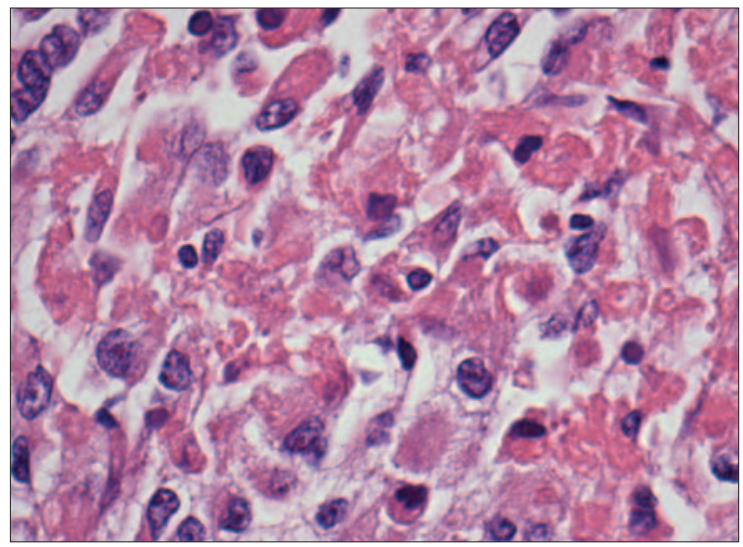

Fig. 2. Histological section showing cytoplasmic eosinophilic inclusions and nuclei with prominent nucleoli (hematoxylin-eosin stain, original magnification $\times 40$ ).

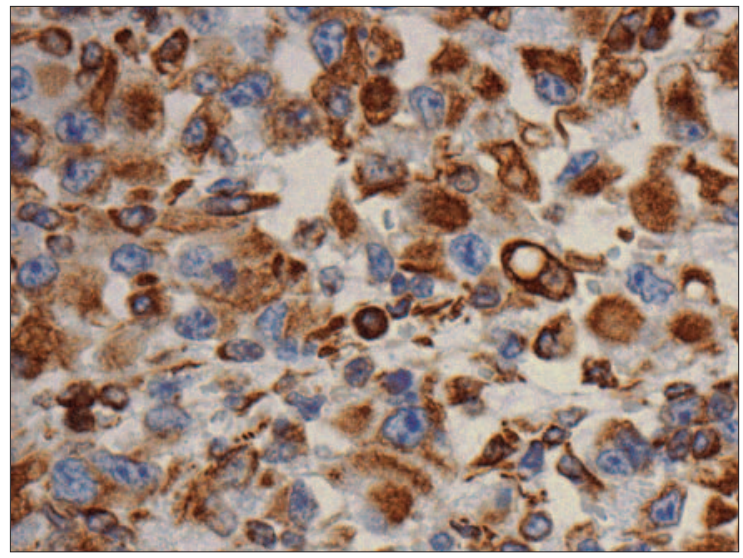

Fig. 4. Histological section showing strong cytoplasmic positivity for vimentin (vimentin stain, original magnification $\times 40$ ). 


\section{Discussion}

Primary carcinomas with rhabdoid features have been reported in various anatomical sites including the bladder, ${ }^{3,4}$ the prostate, ${ }^{5}$ the liver, ${ }^{6,7}$ the uterus, ${ }^{8-11}$ the central nervous system ${ }^{12-16}$ and the vulva. ${ }^{17,18}$ In the kidney, pure rhabdoid carcinomas are usually found in the pediatric population, in which they account for $2 \%$ of pediatric renal tumours. ${ }^{19,20}$ Pure rhabdoid carcinomas in the pediatric population were first described as a variant of Wilms tumour by Beckwith and Palmer in $1978,{ }^{21}$ however, it is now clear that they are a distinct malignancy. ${ }^{22}$ Conversely, in adults, pure rhabdoid variant RCC is exceedingly rare, with only 5 reports in the literature. ${ }^{23-27}$ Gokden and colleagues ${ }^{1}$ proposed that in several of these cases, partial examination may have missed a mixed RCC. Renal cell carcinoma with rhabdoid features are more commonly found alongside clear-cell carcinoma in adults and, in one recent report, alongside chromophobe carcinoma. ${ }^{28}$ In 4 retrospective series of RCC patients, encompassing a total of 1131 patients, the incidence of rhabdoid features ranged from $3 \%$ to $7 \%$ of RCC cases. In Gokden and colleagues $^{\prime 1}$ review of 480 patients, 23 had rhabdoid features mixed with clear-cell carcinoma. Leroy and coauthor ${ }^{29}$ found 14 rhabdoid tumours in 310 cases. Shannon and colleagues ${ }^{\prime 27}$ series of 68 RCC cases yielded 5 rhabdoid tumours. Kuroiwa and coauthors ${ }^{2}$ found 8 cases among 253 cases of RCC.

Whether alone or in combination, rhabdoid features are a marker of poor prognosis. These tumours are more likely to present at higher grades, twice as likely to show extrarenal invasion and more likely to metastasize. ${ }^{1}$ It is thought that this malignant behaviour results from high cell-proliferative activity. ${ }^{2}$ Median patient survival was found to be only 8 months in some studies. ${ }^{2,29}$

It remains unclear whether rhabdoid features arise de novo or from other histological types of RCC. Some propose that they represent divergent differentiation of established pathological subtypes, much like sarcomatoid change, which also carries poor prognostic implications. Others suggest these features represent the end point of clonal evolution on a continuum beginning with clear-cell carcinoma. ${ }^{2}$ Although our case does not clarify the pathogenesis of this disease, it certainly adds to the growing body of literature confirming the aggressive nature of rhaboid RCC in adults.
Sorafenib is an oral multikinase inhibitor that was originally identified as a Raf kinase inhibitor. It was also found to inhibit other receptors, including vascular endothelial growth factor receptor 1,2 and 3. The recent Treatment Approaches in Renal Cancer Global Evaluation Trial ${ }^{30}$ was an international phase 3 study, in which 903 patients who were resistant to prior systemic therapy were randomized to oral sorafenib at a dose of $400 \mathrm{mg}$ twice daily continuously, or placebo. The primary end point of the study was overall survival and the main secondary end point was progression-free survival (PFS). Most patients had clear-cell histology. Ninetythree percent of patients had had nephrectomy and $82 \%$ had received cytokine therapy as their prior systemic treatment. The median duration of treatment was 23 weeks in the sorafenib group and 12 weeks in the placebo group.

The first analysis of overall survival was performed immediately before crossover was allowed, when 220 deaths ( $41 \%$ of the protocol-defined 540 deaths) had occurred. With a median follow-up of 6.6 months, the median actuarial overall survival was 14.7 months in the placebo group but had not been reached in the sorafenib arm, for a hazard ratio (HR) of 0.72 (95\% confidence interval [Cl] $0.54-0.94, p=0.02)$. When survival was assessed 6 months later, 216 of 452 patients receiving placebo had switched to sorafenib and 367 deaths had occurred. Median overall survival was 19.3 months in the sorafenib group and 15.9 months in the placebo group, with an HR of 0.77 (95\% Cl 0.63-0.95, $p=0.02$ ). For both analyses, $p$ value was 0.02 , which was less than the prespecified O'Brien-Fleming values for statistical significance for preliminary analyses.

The first analysis of PFS observed a median PFS of 5.5 months in the sorafenib arm, compared with 2.8 months in the placebo arm, with an HR of 0.44 (95\% Cl 0.35-0.55, $p<0.001)$. Best radiological response was assessed by independent reviewers. Among the 451 patients in the sorafenib group, 1 patient had a complete response and 43 patients (10\%) had a partial response; $333(74 \%)$ had stable disease. In the placebo group of 452 patients, no patients had a complete response, 8 patients $(2 \%)$ had a partial response and 239 patients (53\%) had stable disease. Among the 44 patients with a complete or partial response on sorafenib, the median time to response was 80 (range 35-275) days and the median duration of response was 182 (range 36-378) days. 
Kapoor et al.

The results of this phase 3 trial have demonstrated that sorafenib has a significantly better PFS compared with placebo in patients with advanced RCC who have received prior systemic therapy. The trial reports a large PFS benefit with a high stable-disease rate but a low objective response rate. Whether similar outcomes can be achieved in patients with non-clear-cell histology remains unclear. This report details response to sorafenib with overall stable disease in a patient with adult rhabdoid RCC. Other reasonable agents to treat this patient would have been sunitinib or temsirolimus, although there is a lack of data of the potential efficacy of these agents in rhabdoid RCC patients. Further study and larger case series are needed to fully clarify the natural history and ideal treatment regimen for these aggressive tumours.

\section{Conclusion}

A review of the literature confirms that adult rhabdoid RCC is a rare but aggressive tumour with a distinctly poor prognosis. In our patient, sorafenib appeared to confer prolonged disease stabilization and warrants further study in this and other rare subtypes of RCC.

From the *Division of Urology, Department of Surgery, McMaster University, Hamilton, Ont., and the †Section of Genito-Urinary Oncology, Juravinski Cancer Centre, Hamilton, Ont.

This article has been peer reviewed.

Competing interests: None declared.

\section{References}

1. Gokden N, Nappi O, Swanson PE, et al. Renal cell carcinoma with rhabdoid features. Am J Surg Pathol 2000;24:1329-38.

2. Kuroiwa K, Kinoshita Y, Shiratsuchi H, et al. Renal cell carcinoma with rhabdoid features: an aggressive neoplasm. Histopathology 2002;41:538-48.

3. Egawa S, Uchida T, Koshiba K, et al. Malignant fibrous histiocytoma of the bladder with focal rhabdoid tumor differentiation. J Urol 1994;151:154-6.

4. Harris M, Eyden BP, Joglekar VM. Rhabdoid tumor of the bladder: a histologic, ultrastructural and immunohistochemical study. Histopathology 1987;11:1083-92.

5. Ekfors TO, Aho HJ, Kekomäki M. Malignant rhabdoid tumor of the prostatic region. Immunohistological and ultrastructural evidence for epithelial origin. Virchows Arch A Pathol Anat Histopathol 1985;406:381-8.

6. Foschini MP, Eyken PV, Brock PR, et al. Malignant rhabdoid tumor of the liver. A case report. Histopathology 1992;20:157-65.

7. Hunt SJ, Anderson WD. Malignant rhabdoid tumor of the liver. A distinct clinicopathologic entity. Am J Clin Pathol 1990;94:645-8.
8. Cattani MG, Viale G, Santini D, et al. Malignant rhabdoid tumor of the uterus: an immunohistochemical and ultrastructural study. Virchows Arch A Pathol Anat Histopathol 1992; 420:459-62.

9. Cho KR, Rosenshein NB, Epstein Jl. Malignant rhabdoid tumor of the uterus. Int J Gynecol Pathol 1989;8:381-7.

10. Mount SL, Lee KR, Taaties DJ. Carcinosarcoma (malignant mixed Mullerian tumor) of the uterus with a rhabdoid tumor component. An immunohistochemical, ultrastructural, and immunoelectron microscope case study. Am I Clin Pathol 1995; 103:235-9.

11. Niemann TH, Goetz SP, Benda JA, et al. Malignant rhabdoid tumor of the uterus: report of case with findings in a cervical smear. Diagn Cytopathol 1994;10:54-9.

12. Agranovich AL, Ang LC, Griebel RW, et al. Malignant rhabdoid tumor of the central nervous system with subarachnoid dissemination. Surg Neurol 1992;37:410-4.

13. Biggs PJ, Garen PD, Powers JM, et al. Malignant rhabdoid tumor of the central nervous system. Hum Pathol 1987;18:332-7.

14. Horn M, Schlote W, Lerch KD, et al. Malignant rhabdoid tumor: primary intracranial manifestation in an adult. Acta Neuropathol 1992;83:445-8.

15. Kepes JJ, Moral LA, Wilkinson SB, et al. Rhabdoid transformation of tumor cells in meningiomas: a histopathologic indication of increased proliferative activity. Am I Surg Pathol 1998;22:231-8.

16. Weeks DA, Beckwith JB, Mierau GW, et al. Renal neoplasms mimicking rhabdoid tumor of kidney. A report from the National Wilms' Tumor Study Pathology Center. Am I Surg Pathol 1991;15:1042-54.

17. Matias C, Nunes JFM, Vicente LF, et al. Primary malignant rhabdoid tumor of the vulva. Histopathology 1990;17:576-8.

18. Perrone T, Swanson PE, Twiggs L, et al. Malignant rhabdoid tumor of the vulva: Is distinction from epithelioid sarcoma possible? A pathologic and immunohistochemical study. Am I Surg Pathol 1989;13:848-58.

19. Vujanic GM, Sandstedt B, Harms D, et al. Rhabdoid tumor of the kidney: a clinicopathological study of 22 patients from the International Society of Paediatric Oncology (SIOP) nephroblastoma file. Histopathology 1996;28:333-40.

20. Zderic SA. Renal and adrenal tumors in children. Urol Clin North Am 2004;31:607-17.

21. Beckwith JB, Palmer NF. Histolpathology and prognosis of Wilms' tumor results from the first National Wilms' Tumor Study. Cancer 1978;41:1937-48.

22. Palmer NF, Sutow W. Clinical aspects of the rhabdoid tumor of the kidney: a report of the National Wilms' Tumor Study Group. Med Pediatr Oncol 1983;1 1:242-5.

23. Lowe W, Weiss RM, Todd MB, et al. Malignant rhabdoid tumor of the kidney in an adult. J Urol 1990;143:110-2

24. Clausen HV, Horn T, Anagnostaki L, et al. Malignant rhabdoid tumor of the kidney in an adult: a case report with immunohistochemical and ultrastructural investigation. Scand I Urol Nephrol Supp/ 1994;157:123-8.

25. Ebbinghaus SW, Herrera G, Marshall ME. Rhabdoid tumor of the kidney in an adult: review of the literature and report of a case responding to iterleukin-2. Cancer Biother 1995; 10:237-41.

26. Peng HQ, Stanek AE, Teichberg S, et al. Malignant rhabdoid tumor of the kidney in an adult: a case report and review of the literature. Arch Pathol Lab Med 2003; 127:e371-3.

27. Shannon B, Wisniewski ZS, Bentel J, et al. Adult rhabdoid renal cell carcinoma. Arch Pathol Lab Med 2002;126:1506-10.

28. Shannon B, Cohen RJ. Rhabdoid differentiation of chromophobe renal cell carcinoma. Pathology 2003;35:228-30.

29. Leroy X, Zini L, Buob D, et al. Renal cell carcinoma with rhabdoid features. An aggressive neoplasm with overexpression of p53. Arch Pathol Lab Med 2007;131:103-6.

30. Escudier B, Eisen T, Stadler WM, et al; TARGET Study Group. Sorafenib in advanced clear-cell renal-cell carcinoma. N Engl J Med 2007;356:125-34.

Correspondence: Dr. Anil Kapoor, Genito-Urinary Disease Site, Juravinski Cancer Centre, McMaster University, St. Joseph's Hospital, 50 Charlton Ave. E., Hamilton ON L8N 4A6; kapoor4@mcmaster.ca 